\title{
Alcohol drinking and breast cancer
}

\author{
Duan-Jun Tan, Julie S. Barber, Peter G. Shields \\ Division of Cancer Genetics and Molecular Epidemiology, Lombardi Comprehensive Cancer Center, \\ Georgetown University Medical Center, NW, Washington, DC, USA.
}

\begin{abstract}
Breast cancer is a multifactorial disease that is triggered by gene-environment interactions. Epidemiological research has identified alcohol consumption as a significant non-hormonal-related and consistent risk factor, and is thus a preventable cause of breast cancer. The reasons why alcohol drinking increase breast cancer risk are unclear, and several hypotheses exist. The perturbation of estrogen metabolism and response appears to one mechanism underlying the association. Alcohol consumption also increases breast density in postmenopausal women and affects sex steroid levels. Other plausible mechanisms include: (1) mutagenesis by acetaldehyde, which is a metabolite of ethanol; (2) by enhancing the susceptibility of the mammary gland to carcinogenesis by affecting DNA repair, stimulating cell proliferation or altering mammary gland structural development; (3) influencing the disposition and function of essential nutrients or dietary factors considered cancer protective (e.g. affecting folate and one-carbon metabolism pathways); (4) inducing genome instability and DNA damage; and (5) inducing oxidative damage via ethanol or estrogen metabolism. To better understand the etiological nature of the effect of alcohol on breast carcinogenesis, further studies at the cellular and molecular levels on the interaction between ethanol and other risk factors, estrogen, carcinogens are needed.
\end{abstract}

Keywords: Acetaldehyde; Alcohol dehydrogenase; Alcohol drinking; Breast neoplasms; Cancer risk; DNA damage; Epidemiology; Estrogen; Ethanol metabolism; Genetics; Polymorphism; Risk factors

\section{Introduction}

Breast cancer is a multifactorial disease that is triggered by gene-environment interactions. Much is known about the causes of breast cancer, but the known risk factors account for $<50 \%$ of the variability among women [1]. Intense epidemiological research has been directed at understanding the relationship between breast cancer and alcohol consumption during the past two decades. Alcohol drinking is among the only non-hormonal-related risk factor known to

Correspondence to: Peter G. Shields, MD, Professor of Medicine and Oncology, Lombardi Comprehensive Cancer Center, Georgetown University Medical Center, 3800 Reservoir Road, NW, LL Level, Room S-150, Box 571465, Washington, DC 20057-1465, USA. E-mail: pgs2@georgetown.edu; Tel: +1 202687 0003; Fax: +1202687 0004

Received: 14/11/04

Accepted: 13/02/06

First published online 06/03/06

BCO/310/2004/FO cause breast cancer (although there may be an indirect relationship). However, the reasons for this are unclear, and several hypotheses exist, including mutagenesis induced by acetaldehyde, perturbation of estrogen metabolism and response, altering breast epithelial cell susceptibility, induction of oxidative damage, and/ or by affecting folate and one-carbon metabolism pathways. Most well-defined risk factors such as age, family history of breast cancer, early menarche, late menopause, late age at first full-term birth, and benign breast disease are difficult or impossible to alter [2]. However, alcohol consumption can be modified. The study of alcohol also can be used as a paradigm for breast carcinogenesis and nutritional carcinogenesis, because of the multiple possible pathways that it affects, and there are interactions with dietary risk factors. This review focuses on several key questions and recent advances of the relationship between alcohol consumption and breast cancer, 
including breast cancer risk induced by alcohol and the potential mechanisms and factors of alcoholassociated carcinogenesis.

Within the USA, approximately 14000 women are diagnosed yearly with breast cancer attributed to alcohol consumption [3], which is more than the number of cases diagnosed in women who come from high-risk families [4]. A 1997 publication by the World Cancer Research Fund and the American Institute for Cancer Research stated that the role of alcohol in increasing breast cancer risk was among the most consistent findings regarding the influence of dietary factors on breast cancer risk [5], and research since then has continued to demonstrate the relationship between alcohol consumption and breast cancer. A review of research through 2001 concluded that alcohol intake has been associated in both premenopausal and postmenopausal women, regardless of the type of alcohol consumed [6]. Epidemiological studies have indicated that the risk of breast cancer increases between $7 \%$ and $9 \%$ for each $10-12 \mathrm{~g}$ of alcohol consumed per day (equal to about 1 drink) [7], and risk increases by $41 \%$ with the consumption of 2-5 drinks per day [8]. Furthermore, the Collaborative Group on Hormonal Factors in Breast Cancer concluded that alcohol is an independent risk factor, and is not confounded by other risks such as smoking $[7,9]$. There are sufficient experimental animal studies to implicate ethanol as a human carcinogen. In Singletary and Gapstur's review of studies [6,10], five studies were mentioned in which mammary tumor development was increased in female rats that were fed ethanol. Another publication demonstrated an increase in metastasis of implanted breast cancer cells in rats [11]. In conjunction with human studies and cell culture experiments, these animal models support possible biological mechanisms for the role of alcohol in increasing breast cancer risk [6].

\section{Alcohol drinking and breast cancer risk}

Amount of alcohol consumed: The majority of epidemiological studies have indicated a positive association between consumption of alcohol and an increase in breast cancer risk, although the magnitude of the risk differs. In a collaborative reanalysis of data from 53 separate studies, the relative risk of breast cancer was $1.32(95 \% \mathrm{Cl}, 1.19-1.45)$ for an intake of $35-44 \mathrm{~g} /$ day, and increased to a relative risk of $1.46(95 \% \mathrm{Cl}, 1.33-1.61)$ with a consumption of $>44 \mathrm{~g} /$ day, in comparison with women with no alcohol consumption [12]. In a case-control study conducted in Long Island, New York, Bowlin et al. studied the relationship between breast cancer risk and recent alcohol use, duration of alcohol consumption, and age at which drinking began [13]. The study suggested that the intensity of drinking (drinks per day) was the most important risk factor for breast cancer, having more effect than recent alcohol use or duration of drinking [13]. It was concluded that women who drank alcohol were at a $40-45 \%$ increased risk of breast cancer compared to those who never consumed alcohol $(\mathrm{OR}=1.47$, $95 \% \mathrm{Cl}, 1.17-1.84)$. This relationship between intake and risk was dose-responsive; women who consumed $>5 \mathrm{~g} /$ day of alcohol (less than one-half of a drink) had a $50 \%$ increased risk compared to never-drinkers, thereby indicating that even moderate amounts of alcohol consumption still leads to an increased risk. A 2002 meta-analysis conducted by the Collaborative Group on Hormonal Factors in Breast Cancer concluded that the overall relative risk of breast cancer increases by $7.1 \%$ for each additional $10 \mathrm{~g} /$ day intake of alcohol [12]. Another study found a linear increase up to an intake of $60 \mathrm{~g} / \mathrm{day}$, and with every $10 \mathrm{~g} /$ day increase above the initial 60 , the risk increases with 9\% [7]. Although the risk percentages vary among studies, it is agreed that the risk associated with alcohol consumption is indeed dose-dependent, increasing with an increase intake in alcohol.

Petri et al. reported that increased alcohol intake was directly associated with a moderately increased risk of breast cancer when menopausal status was not considered [14]. Without dividing cases by menopausal status, a trend of increasing risk with increasing alcohol intake was observed. However, following stratification into pre- and postmenopausal cases, the data indicated that premenopausal women consuming more than 27 drinks per week had an increased relative risk for breast cancer, whereas postmenopausal women consuming the same amount of alcohol per week did not have an increased risk. Premenopausal women were found to have a relative risk of breast cancer of 1.35 with the consumption of over 14 drinks per week, while postmenopausal women had a risk of 1.06 in this consumption category. This particular study indicated that total alcohol intake had an effect on the relative risk of breast cancer specifically among premenopausal individuals, but following menopause, an association was not found between breast cancer risk and alcohol intake. Furthermore, among premenopausal women, no relative risk difference was identified among the specific type of alcohol consumed, unlike in the postmenopausal population where a high intake of spirits in particular yielded a significant increase in risk [14].

Drinking age: Data on the age at which women begin drinking alcohol and its influence on increased breast cancer susceptibility has been varied. Some studies show no relationship to age at which one 
started drinking, increased frequency or amount of consumption during adolescence or young adulthood [15-18], whereas others show positive associations [19,20]. A 1995 study by Colditz et al. suggested that delaying the onset of drinking could lead to a reduction in breast cancer risk [21], but since then several studies found no association between age and risk [22-25], while others have been positive $[19,20,26]$. The relationship between early alcohol intake and an increased in breast cancer could be confounded by a cumulative effect (found in two case-control studies by Longnecker) [20,24,27], rather than from increased sensitivity during early age exposure. Although age at which alcohol consumption began was not relevant, Bowlin et al. discovered that the number of years in which alcohol was consumed does influence the risk of developing breast cancer. Although the increase of risk from drinking was significant for both groups, premenopausal women were found to have the higher risk [13]. Drinking alcohol earlier in life appeared to influence neither postmenopausal breast cancer rate nor the association between recent alcohol intake and relative risk of breast cancer. The discrepancies between these studies may be attributed to the difficulty in finding populations with high average alcohol intake or underreporting of alcohol intake by the participants in the study. Among the several studies that have been able to examine lifetime drinking, many have observed that recent drinking, drinking later in life or lifetime consumption are more predictive of risk $[15,16,17,28]$. For example, Tjonneland et al. found that among postmenopausal women, recent intake of alcohol is a more accurate predictor of breast cancer risk than is earlier lifetime exposure [16]. The varied results from these studies indicates that further research, separating age of drinking, intensity of drinking, and duration of drinking, is necessary to understand the relationship between age at which alcohol consumption begins and breast cancer.

Type of alcohol consumed: Some studies have examined the relationship between the type of alcohol consumed and risk of breast cancer. A metaanalysis based on 13 studies which reported risks based on consumption of beer, wine, and spirits concluded relatively no difference between intake and risk based on type of beverage [7]. Using 14 or fewer drinks per week of each type of beverage, the relative risk for beer was 0.96 in comparison with wine and the relative risk for spirits was 1.01 in comparison with wine. A separate population-based cohort study determined that for premenopausal women under 70 years of age risk was independent of type of alcohol, but after age 70 postmenopausal risks differed based on type [14]. Specifically, there was a significant increase in relative risk of breast cancer for postmenopausal women who consumed more than six drinks of spirits per week, in comparison to those who averaged $<1$ per week. Despite experimental studies suggesting that certain non-alcoholic contaminants in wine, such as resveratrol, may inhibit cancer initiation, promotion, and growth [29,30], neither Ellison's meta-analysis nor Petri et al.'s cohort study showed any beneficial affects of wine in reducing breast cancer risk in comparison to other forms of alcohol.

Alcohol and nutrients: Some dietary factors may modify the association of alcohol with breast cancer. Alcohol consumption influences the disposition and function of essential nutrients or dietary factors considered cancer protective through the modification of folate status or a decrease of concentrations of B-carotene, lutein/zeaxanthin, and vitamin C [31]. Epidemiological studies show that alcohol consumption results in the decrease of blood concentrations of these latter nutrients [32-34]. Lutein and $\alpha$-carotene may decrease the activity of cytochrome P450 1A2, an activator of procarcinogens [35], and $\beta$-cryptoxanthin might stimulate the expression of the retinoblastoma gene [36], and the p53-related p73 gene [36]. Retinoids (vitamin $A$ and its derivatives) are known to exert profound effects on cellular growth, cellular differentiation, and apoptosis, thereby controlling carcinogenesis. Alcohol acts as a competitive inhibitor of vitamin A oxidation to retinoic acid involving alcohol dehydrogenases (ADHs) and acetaldehyde dehydrogenases (ALDHs), while alcohol-induced cytochrome P450 enzymes (CYP), particularly CYP 2E1, enhance catabolism of vitamin $A$ and retinoic acid. Alcohol also alters retinoid homeostasis by increasing vitamin A mobilization from the liver to extrahepatic tissues. As a consequence, longterm and excessive alcohol intake results in impaired status of retinoic acid [37]. Taken together, these studies suggest that alcohol consumption may be associated with increased breast cancer risk, in part because of the negative impact of alcohol intake on the disposition or biological efficacy of dietary factors believed to be cancer protective.

Folate is required for DNA synthesis, repair, and methylation. Low folate status has been implicated in carcinogenesis, possibly as a result of a higher rate of genetic damage. Zhang et al. indicated that higher alcohol consumption and lower intake of the water-soluble vitamin folate exhibited a significantly higher relative risk for breast cancer [38]. Among women who consumed at least $15 \mathrm{~g} /$ day of alcohol, the risk of breast cancer was highest among those with total folate intake of $<300 \mu \mathrm{g} /$ day [38]. The estimated hazard ratio of an alcohol consumption of $40 \mathrm{~g} /$ day or more was 2.00 for women with intakes of $200 \mu \mathrm{g} /$ day of folate and 0.77 for $400 \mu \mathrm{g} /$ day of 
folate [39]. A Swiss case-control study also reported a significant inverse association between folate intake and risk of breast cancer in postmenopausal women, and this association was stronger in women who consumed alcohol [40]. Although many studies show that the excess risk of breast cancer associated with alcohol consumption may be reduced by adequate folate intake $[38,39,40,41]$, recent results from the American Cancer Society do not support an association with folate, methionine or an interaction between folate and alcohol [42].

Folate deficiency decreases levels of S-adenosylmethionine (SAM), causes DNA hypomethylation and protooncogene activation, and induces uracil misincorporation in DNA synthesis. This results in deficiencies during the DNA repair process and leads to chromosome breaks in human beings, which could directly contribute to an increase in cancer risk [43-46]. Alcohol consumption may modify the association of folate intake with breast cancer risk by interfering with several aspects of normal folate transport and metabolism including dietary intake, intestinal absorption, transport to tissues, storage, and release by the liver, thereby disrupting folate supply to tissues. In combination with low folate intake, alcohol and/or its primary metabolite acetaldehyde may alter folate or methionine metabolism, so that an imbalance in DNA methlyation or in the DNA damage/repair process could lead to DNA instability or inappropriate gene expression [14,43,47-51].

Alcohol and mammographical breast density: Increased breast density defined mammographically is a known risk factor for development of breast cancer [52,53], associated with a four- to six-fold increase in risk $[52,53,54-58,59]$. There are a variety of reasons for this association, including the development of premalignant lesions, elevated growth factors, obesityrelated cytokines, or increased estrogen production within the breast due to overactive aromatase [60]. Increased breast density is of particular interest because it is influenced by lifestyle factors, including alcohol intake.

Epidemiological studies have shown that alcohol consumption is associated with an increased mammographical density of the breast parenchyma [6, $61,62]$. Alcohol intake may influence early as well as late stages of breast cancer. With regard to former, there is a well-established relationship between the proportion of breast volume occupied by mammographic parenchymal (fibroglandular) densities and breast cancer risk [63]. Ethanol consumption at levels up to $25 \%$ of calories have been reported to increase the mammary gland density of terminal end buds, the target structures from which mammary adenocarcinomas develop, and to stimulate the rate of cell proliferation in terminal end buds $[10,11,64]$. Another study by Vachon et al. determined that premenopausal women who were never-drinkers over the previous 12 months had a multivariate-adjusted mean breast density of $39 \%$, whereas those who consumed $\leqslant 3.9 \mathrm{~g} /$ day had a breast density of $45 \%(95 \% \mathrm{Cl}$, 40-45) and those consuming $>3.9 \mathrm{~g} /$ day had a breast density of $42 \%$ [65]. In postmenopausal women an increase was noticeable, but not as great, with mean densities of $31 \%, 32 \%$, and $33 \%$ for the same increasing categories of alcohol intake. When looking at specific types of alcohol, it was determined that breast density increased with consumption of white wine $(21 \%, 31 \%$, and $34 \%$ using the same increasing $\mathrm{g} /$ day measurement), but decreased with red wine intake (34\%, 32\%, and $28 \%)$. To date, other studies have not addressed the specific increase of breast density based specifically on type of alcohol consumed.

\section{Ethanol metabolism and procarcinogens}

Most tissues of the body, including breast, contain the necessary enzymes for the oxidative and nonoxidative metabolism of ethanol. Ethanol can be oxidized by three enzyme systems: the ADHs, cytochrome P-450 2E1 (CYP2E1), and catalase. The product of all three reactions is acetaldehyde, which is then further metabolized to acetate by ALDH, xanthine oxoreductase (XOR), and aldehyde oxidase (AOX) [67]. ADH is the enzyme responsible for alcohol metabolism when blood and tissue ethanol concentrations are low. However, when tissue levels exceed $10 \mathrm{mM}$ (approximately $50 \mathrm{mg} / \mathrm{dL}$ ), the microsomal ethanol-oxidizing system (MEOS) containing CYP2E1 can also contribute. The MEOS uses nicotinamide adenine dinucleotide phosphate (NADPH) and molecular oxygen. Peroxisomal catalase uses hydrogen peroxide as an oxidizing agent. It is the least important of the three pathways [66].

Consistent evidence from animal experiments shows that ethanol modulates chemically induced carcinogenesis. Although ethanol has not been identified as a genotoxic carcinogen, in some experimental models it can act as a co-carcinogen by influencing physiological processes associated with the initiation and promotion stages of carcinogenesis [67]. Ethanol might cause cancer by (Figure 1):

1. Production of acetaldehyde, which is a weak mutagen and carcinogen [68]: Ethanol can be metabolized to acetaldehyde in the liver, breast, and other tissues [69]. As a result of experimental animal studies, the International Agency for Research on Cancer (IARC) has considered that there is sufficient evidence for the carcinogenicity of acetaldehyde, the major metabolite of ethanol, in 


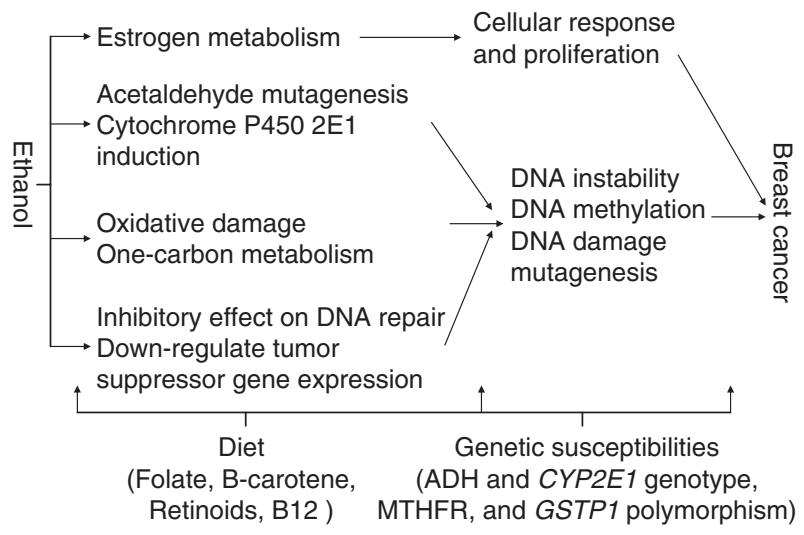

Figure 1.

Hypothesized mechanistic relationships.

experimental animals. Acetaldehyde is carcinogenic in rodents [70] and causes sister chromatid exchanges and chromosomal aberrations in human cells [71]. It binds rapidly to cellular proteins and DNA, leading to protein adducts, measurable in both experimental animals and human beings, and to DNA adducts, especially N2-ethyl-2'deoxyguanosine [72].

2. Induction of cytochrome P-4502E1 (CYP2E1): Some chemicals, such as $N$-nitrosamines are potential human breast carcinogens, are metabolized to mutagenic and/or carcinogenic metabolites by cytochrome CYP2E1 [73]. In addition, CYP2E1 also plays a major role in activation of several other procarcinogens, such as benzene, a known rat mammary carcinogen [74] as well as urethane and styrene [75]. Moreover, CYP2E1 is effective in producing reactive oxygen species such as superoxide, hydrogen radical, and hydrogen peroxide both in the presence and absence of substrates [76], which in turn can damage DNA. Ethanol has been shown to induce CYP2E1 [77] and enhance rat mammary carcinogenesis induced by 7,12-dimethylbenz(a)anthracene [78], and $N$-methylnitrosourea [79].

3. Accumulation of iron and associated oxidative stress: Gastro et al. detected bioactivation of ethanol to acetaldehyde and 1-hydroxyethyl free radicals by cytosolic xanthine oxidoreductase in rat breast tissue, which suggests that ethanol metabolism can be mediated by other enzymes in addition to ADH and cytochrome P450, and can yield multiple free radical species [69]. Metal ions, specifically iron, are necessary for the production of hydroxy radicals. In human beings, elevated body iron storage has been shown to increase the risk of several cancers including breast cancer [81]. For instance, a six-fold higher tissue ferritin concentration has been measured in malignant carcinoma of the breast compared to normal or benign tissue [81]. Furthermore, transferrin and tumor cell transferrin receptor proteins were elevated in breast carcinoma compared to normal or benign cells $[80,82]$. Chronic alcohol intake is associated with increased accumulation of iron. Both alcohol and iron are known prooxidants. The metabolism of alcohol through CYP2E1 can lead to generation of superoxide and hydrogen peroxide. On the other hand, hydrogen peroxide can react with ferrous iron $\left(\mathrm{Fe}^{2+}\right)$, through the Fenton reaction, and generate hydroxyl radicals, which are highly reactive. Hydroxyl radicals can react with lipid molecules, initiating chain reactions that lead to lipid peroxidation and generation of products, such as acrolein, crotonaldehyde, malondialdehyde, and 4-hydroxynonenal (4-HNE). The 4-HNE is known to cause mutations of the p53 gene [83].

4. Inhibitory effect of ethanol on DNA repair: Some carcinogen-DNA adduct has been shown to be responsible for the genotoxic and mutagenic effects [82,83]. Ethanol inhibits benzo[a]pyrene diol-epoxide (BPDE)-DNA adduct removal and increases 8-oxo-deoxyguanosine formation in human mammary epithelial cells. BP-treated cells exposed to $25 \mathrm{mM}$ ethanol exhibited a significant two-fold increase in 8-oxo-deoxyguanosine (8oxo-deG) adducts compared to BP-treated cells alone. In addition, the best-studied DNA adduct from acetaldehyde is N2-ethyl-2'-deoxyguanosine, which is increased in liver DNA obtained from ethanol-treated rodents and in white blood cells obtained from human alcohol abusers. Ethanol-associated inhibition of carcinogen-DNA adduct removal in non-neoplastic human mammary cells may be another biological mechanism used to explain the increased risk for breast cancer among women consuming alcohol $[82,84]$.

5. Induction of increased production of inhibitory guanine nucleotide regulatory proteins and components of extracellular signal-regulated kinasemitogen-activated protein kinase signaling: Alcohol also can inhibit phase II enzyme-mediated carcinogen detoxification and impair liver clearance of carcinogens, resulting in their increased circulation among extrahepatic tissues [85]. Moreover, alcohol intake may enhance the susceptibility of the rodent mammary gland to carcinogen-induced damage by altering mammary gland structural development and by simulating cell proliferation in the target structures for mammary tumorigenesis, terminal end buds, and changes associated with decreased circulating progesterone $[11,64]$. IGF-I and IGF-II are strong mitogens for breast cancer and IGF-I can act together with estrogen to stimulate cell proliferation and tissue development 
$[86,87]$. Alcohol can influence IGF-I level in human beings, and in in vitro and animal studies, alcohol has been reported to variably modify cell division and intracellular signaling pathways, partly dependent on the dose of ethanol [87-91].

\section{Inherited susceptibility}

Genome instability and DNA damage: The ability of ethanol to induce genomic damage has recently been assessed by using cytokinesis block micronucleus (CBMN) assays, a reliable and established method to detect chromosome damage. Chronic treatment with physiological concentrations of ethanol $(0.36 \%, 1.36 \%)$ induces micronuclei, nucleoplasmic bridges, and nuclear buds, which are indicative of chromosome loss and breakage, chromosome rearrangement and gene amplification, respectively. The occurrence of the specific genome instability event of chromosome 17 aneuploidy supports the hypothesis that alcohol induces genotoxic events that are relevant to cancer risk including breast cancer $[89,92]$. Hussien et al. provided evidence that alcohol intake is positively correlated with the level of DNA damage detected by the modified comet assay in breast cancer [49].

Tumor suppressor gene expression: The tumor suppressor gene BRCA1 plays a role in cell cycle regulation, apoptosis, and DNA repair and recombination pathways that may be related to its tumor suppressor function [93]. Mutations of the breast cancer susceptibility gene BRCA1 (17q21) confer an increased risk for breast and ovarian cancers [93,94-96]. Alcohol can down-regulate $B R C A 1$ and partially reverses the $B R C A 1$-mediated Inhibition of ER- $\alpha$ transcriptional activity. Inasmuch as BRCA1 is a potent repressor of $E R-\alpha$ transcriptional activity, the ethanol-mediated down-regulation of BRCA1 expression could contribute to increased intrinsic transcriptional activity of ER- $\alpha$ independent of any changes in ER- $\alpha$ levels [97]. This supports the suggestion that the mechanisms that might contribute to alcohol-related breast cancer are related to $B R C A 1$ pathways and increased estrogen responsiveness [4,97].

DNA Methylation: DNA methylation is an important determinant in controlling gene expression, whereby hypermethylation has a silencing effect on genes, and hypomethylation may lead to increased gene expression. For example, DNA methylation is an important epigenetic determinant of gene regulation of protooncogenes and tumor suppressor genes, as well as the estrogen receptor gene [98,99]. Breast cancerogenesis could be initiated through activation of protooncogenes by hypomethylation of their promoter regions $[98,100]$ through inactivation of tumor suppressor genes by hypermethylation $[98,101]$ or through alteration of estrogen receptor gene methylation patterns $[98,102]$. Both vitamin B12 and folate are required for DNA methylation and nucleotide synthesis. Thus, folate deficiency may increase the risk of malignancy by causing DNA hypomethylation, inducing uracil misincorporation during DNA synthesis, or both, resulting in deficiency in the DNA repair process and, therefore, DNA strand breaks $[3,44,45,64,98]$. It is also interesting that there is an increase in methyltransferase activity and methylation of $\mathrm{CpG}$ sites after extended periods of folate deficiency [103]. Alcohol consumption can negatively affect folate status in tissues that rapidly proliferate [104] and also may diminish serum vitamin B12 concentrations among healthy, postmenopausal women [105]. Alcohol has a marked impact on methylation capacity, as reflected by decreased levels of SAM and increased levels of S-adenosylhomocysteine (SAH). SAM is a major methyl donor for methylation reactions, whereby it donates a methyl group to many compounds, such as proteins, DNA, RNA, and phospholipids. A decreased SAM : SAH ratio can inhibit activities of many methyltransferases, leading to global hypomethylation of DNA, which is an early feature of neoplastic transformation of epithelial cells. Thus, alcohol-induced inhibition of methionine synthese activity may promote neoplastic growth through decreasing SAM levels [68].

Genetic polymorphisms for breast cancer risk: Genetic susceptibilities for ethanol metabolism can affect breast cancer risk. As acetaldehyde is potentially a carcinogenic factor associated with chronic alcohol consumption, individuals with the $\mathrm{ADH} 1 \mathrm{C}^{\star} 1$ allele seem to be at particular risk, as this allele encodes for a rapidly ethanol metabolizing enzyme leading to increased acetaldehyde levels. Women with the $A D H 1 C(1-1)$ genotype were found to be 1.8 times more at risk for breast cancer than those with the other genotypes [106]. Freudenheim and coworkers found increased breast cancer risk among pre- but not postmenopausal women associated with $A D H 3(1-1)$ compared to $A D H 3(1-2)$, and $A D H 3(2-2)$ genotypes. The breast cancer risk was increased for premenopausal women with the $A D H 3(1-1)$ genotype and alcohol intake above the median compared to lighter drinkers with the $A D H 3(2-2)$ or $A D H 3(1-2)$ genotypes [107]. Hines et al. showed that the $A D H 3$ polymorphism modestly influences the response of some plasma hormones to alcohol consumption, but is not independently associated with breast cancer risk and does not modify the association between alcohol and breast cancer risk [108]. The ADH1B genotype (containing the G47A polymorphism) may be not an independent risk factor for breast cancer, although the possibility was raised that it modifies risk associated with high levels of alcohol consumption [109]. 
Methylenetetrahydrofolate reductase (MTHFR) is a polymorphic enzyme involved in folate metabolism, and plays a role in DNA biosynthesis, methylation, and repair in actively dividing cells. It results in impaired in vitro stability and reduced activity under low folate conditions [99,110-112]. Two common variants in the MTHFR gene (C677T and A1298C) have been associated with a reduced activity of this enzyme, thereby increasing the availability of folate for thymidylate and purine synthesis, while simultaneously increasing the risk of premenopausal, but not postmenopausal, breast cancer $[99,113]$. In population-based studies, the presence of the MTHFR $677 \mathrm{C} \rightarrow$ T polymorphism has been associated with reduced cancer risk when folate status is normal. Intake of folate and other methyl-related nutrients (i.e. methionine, vitamin B6, vitamin B12) and alcohol may influence the effect of the MTHFR $677 \mathrm{C} \rightarrow \mathrm{T}$ polymorphism on cancer risk [114-117]. Persons with the variant MTHFR 677 genotype may be more susceptible to cancer if they have a methylpoor diet (i.e. high alcohol or low folate intake or both). When dietary methyl supply is high, the MTHFR homozygous Val/Val genotype individuals may be at reduced risk of cancer, probably because higher levels of 5,10-methylenetetrahydrofolate may prevent imbalances of nucleotide pools during DNA synthesis. In contrast, when 5-methyltetrahydrofolate is depleted by alcohol consumption, val/val individuals may be less able to compensate, leading to potentially oncogenic alterations in DNA methylation [114].

Chaoi et al. examined the potential association between alcohol consumption and breast cancer risk for alcohol metabolizing enzymes CYP2E1 and $A L D H 2$. They found that the women who consumed alcohol with the CYP2E1 c2 allele containing genotypes had a 1.9-fold risk for developing breast cancer compared to non-drinkers with the CYP2E1 c1/c1 genotype. That suggested that the CYP2E1 c2 allele influences individual susceptibility to breast cancer in alcohol consuming women [118].

Women with a polymorphims in the glutathione Stransferase P1 (GSTP1) gene, involved in the protection against oxidative damage and who consumed alcohol had almost a three-fold risk of breast cancer for having a valine allele, whereas never-drinking women had half this risk. Therefore, the GSTP1 polymorphism also appears to influence individual susceptibility to breast cancer and this effect may be modified by alcohol consumption [119]. Analysis for other glutathione-S-transferase genotypes and alcohol consumption shows that GSTM1 null genotype in ever-drinking women had a 2.5 -fold $(\mathrm{OR}=2.5,95 \%$ $\mathrm{Cl}, 1.1-5.5)$ increased risk of breast cancer compared to the GSTM1 null never-drinkers, and the risk increases with duration and daily amount of alcohol consumption [120]. The cytochrome P450 19 (CYP19) Arg(264)Cys polymorphism modifies breast cancer risk $(\mathrm{OR}=1.5,95 \% \mathrm{Cl}, 1.1-2.2)$, especially in association with alcohol consumption [99].

\section{Alcohol and estrogen status}

Estrogens play a crucial role in the cellular proliferation of both normal and neoplastic breast epithelium. Some studies have proved that cumulative lifetime exposure to estrogen, particularly estradiol, contributes to breast cancer risk [6]. Alcohol's impact on hormone status provides one plausible explanation for an etiological relationship between alcohol and breast carcinogenesis. Alcohol might affect sex steroid levels through several mechanisms. Charlotte et al. showed that levels of estrogens is higher in women who consume more alcohol [121]. Oral ethanol (dose of $0.225 \mathrm{~g} / \mathrm{kg}$ body weight) increased serum estradiol levels significantly by $27-38 \%$ [108]. Alcohol interferes with estrogen pathways in multiple ways. For example, alcohol drinking is associated with decreased menstrual cycle variability, more frequent long cycles, and increased serum and urinary estrogen metabolites, as well as decreased sex hormonebinding globulin, follicle-stimulating hormone, and luteinizing hormone levels [3,122-124]. Ethanol can down-regulate the expression of the tumor suppressor gene BRCA1, a potent inhibitor of estrogen receptor alpha $(E R-\alpha)$ activity, and can increase the transcriptional activity of ER-a, supporting the suggestion that the mechanisms that might contribute to alcohol-related breast cancer are related to BRCA1 pathways and increased estrogen responsiveness [98]. Recent studies that used both in vivo and in vitro systems revealed that ethanol acts similarly to estradiol. Like estradiol, ethanol reduces the activity of the growth-inhibitory TGF- $\beta 1$ and stimulates the activity of TGF- $\beta 3$ in the pituitary gland. Hence, it is hypothesized that ethanol may promote prolactinomas by controlling the cell-regulatory processes in the lactotropes and/or by enhancing the action of estrogen on the lactotropes [125].

\section{Summary}

Alcohol consumption as a risk factor for breast cancer in human beings has received considerable scientific support from epidemiological reports over the past two decades. The biological basis for this action of alcohol has not been firmly established, but is believed to involve, in part, an alcohol-associated stimulation of circulating steroid hormone levels. Ethanol's tumor-promoting action may be linked to elevation of circulating levels of estrogen. The steroid has been shown to promote carcinogenesis in various 
animal model systems by stimulating the rate of mammary gland cell proliferation, as well as by increasing mammary cell carcinogen-DNA adduct formation. Additionally, estrogen-induced tumor induction may involve receptor-mediated cell proliferation with tumor initiation by genotoxic and mutagenic events. Interactions of alcohol with host and environmental factors, alcohol-related various procarcinogens, inherited susceptibility, and methylation have also been involved in the breast carcinogenesis. Further studies at the cellular and molecular levels on the interaction between ethanol and estrogen, carcinogens are needed to better understand ethanol's promotion of breast cancer.

\section{Acknowledgement}

This work was supported by the Department of Defense Funded Breast Cancer Center of Excellence DAMD17-03-1-0446

\section{References}

1. Madigan MP, Ziegler RG, Benichou J, Byrne C, Hoover RN. Proportion of breast cancer cases in the United States explained by well-established risk factors. $J$ Natl Cancer Inst 1995; 87(22): 1681-1685.

2. Megdal SP, Kroenke CH, Laden F, Pukkala E, Schernhammer ES. Night work and breast cancer risk: A systematic review and meta-analysis. Eur $J$ Cancer 2005; 41(13): 2023-2032.

3. Tseng M, Weinberg CR, Umbach DM, Longnecker MP. Calculation of population attributable risk for alcohol and breast cancer (United States). Cancer Causes Control 1999; 10(2): 119-123.

4. Dumitrescu RG, Shields PG. The etiology of alcoholinduced breast cancer. Alcohol 2005; 35(3): 213-225.

5. Glade MJ. Food, nutrition, and the prevention of cancer: a global perspective. American Institute for Cancer Research/World Cancer Research Fund, American Institute for Cancer Research, 1997. Nutrition 1999; 15(6): 523-526.

6. Singletary KW, Gapstur SM. Alcohol and breast cancer: review of epidemiologic and experimental evidence and potential mechanisms. JAMA 2001; 286(17): 2143-2151.

7. Ellison RC, Zhang $\mathrm{Y}$, McLennan CE, Rothman KJ. Exploring the relation of alcohol consumption to risk of breast cancer. Am J Epidemiol 2001; 154(8): 740-747.

8. Smith-Warner SA, Spiegelman D, Yaun SS, et al. Alcohol and breast cancer in women: a pooled analysis of cohort studies. JAMA 1998; 279(7): 535-540.

9. Longnecker MP. Alcoholic beverage consumption in relation to risk of breast cancer: meta-analysis and review. Cancer Causes Control 1994; 5(1): 73-82.

10. Singletary K. Ethanol and experimental breast cancer: a review. Alcohol Clin Exp Res 1997; 21(2): 334-339.

11. Singletary KW, McNary MQ. Influence of ethanol intake on mammary gland morphology and cell proliferation in normal and carcinogen-treated rats. Alcohol Clin Exp Res 1994; 18(5): 1261-1266.
12. Hamajima N, Hirose K, Tajima K, et al. Alcohol, tobacco and breast cancer-collaborative reanalysis of individual data from 53 epidemiological studies, including 58,515 women with breast cancer and 95,067 women without the disease. Br J Cancer 2002; 87(11): 1234-1245.

13. Bowlin SJ, Leske MC, Varma A, et al. Breast cancer risk and alcohol consumption: results from a large casecontrol study. Int J Epidemiol 1997; 26(5): 915-923.

14. Petri AL, Tjonneland A, Gamborg M, et al. Alcohol intake, type of beverage, and risk of breast cancer in pre- and postmenopausal women. Alcohol Clin Exp Res 2004; 28(7): 1084-1090.

15. Marcus PM, Newman B, Millikan RC, et al. The associations of adolescent cigarette smoking, alcoholic beverage consumption, environmental tobacco smoke, and ionizing radiation with subsequent breast cancer risk (United States). Cancer Causes Control 2000; 11(3): 271-278.

16. Tjonneland A, Christensen J, Thomsen BL, et al. Lifetime alcohol consumption and postmenopausal breast cancer rate in Denmark: a prospective cohort study. J Nutr 2004; 134(1): 173-178.

17. Horn-Ross PL, Canchola AJ, West DW, et al. Patterns of alcohol consumption and breast cancer risk in the California Teachers Study cohort. Cancer Epidemiol Biomarkers Prev 2004; 13(3): 405-411.

18. Baumgartner KB, Annegers JF, McPherson RS, et al. Is alcohol intake associated with breast cancer in Hispanic women? The New Mexico Women's Health Study. Ethn Dis 2002; 12(4): 460-469.

19. Harvey EB, Schairer C, Brinton LA, Hoover RN, Fraumeni Jr JF. Alcohol consumption and breast cancer. J Natl Cancer Inst 1987; 78(4): 657-661.

20. van't VP, Kok FJ, Hermus RJ, Sturmans F. Alcohol dose, frequency and age at first exposure in relation to the risk of breast cancer. Int J Epidemiol 1989; 18(3): 511-517.

21. Colditz GA, Frazier AL. Models of breast cancer show that risk is set by events of early life: prevention efforts must shift focus. Cancer Epidemiol Biomarkers Prev 1995; 4(5): 567-571.

22. Smith SJ, Deacon JM, Chilvers CE. Alcohol, smoking, passive smoking and caffeine in relation to breast cancer risk in young women. UK National Case-Control Study Group. Br J Cancer 1994; 70(1): 112-119.

23. Freudenheim JL, Marshall JR, Graham S, et al. Lifetime alcohol consumption and risk of breast cancer. Nutr Cancer 1995; 23(1): 1-11.

24. Longnecker MP, Newcomb PA, Mittendorf R, et al. Risk of breast cancer in relation to lifetime alcohol consumption. J Natl Cancer Inst 1995; 87(12): 923-929.

25. Katsouyanni K, Trichopoulou A, Stuver S, et al. Ethanol and breast cancer: an association that may be both confounded and causal. Int J Cancer 1994; 58(3): 356-361.

26. Schatzkin A, Jones DY, Hoover RN, et al. Alcohol consumption and breast cancer in the epidemiologic follow-up study of the first National Health and Nutrition Examination Survey. N Engl J Med 1987; 316(19): 1169-1173.

27. Longnecker MP, Paganini-Hill A, Ross RK. Lifetime alcohol consumption and breast cancer risk among postmenopausal women in Los Angeles. Cancer Epidemiol Biomarkers Prev 1995; 4(7): 721-725.

28. Longnecker MP, Newcomb PA, Mittendorf R, et al. Risk of breast cancer in relation to lifetime alcohol consumption. J Natl Cancer Inst 1995; 87(12): 923-929. 
29. Jang M, Cai L, Udeani GO, et al. Cancer chemopreventive activity of resveratrol, a natural product derived from grapes. Science 1997; 275(5297): 218-220.

30. Uenobe F, Nakamura S, Miyazawa M. Antimutagenic effect of resveratrol against Trp-P-1. Mutat Res 1997; 373(2): 197-200.

31. Gandini S, Merzenich H, Robertson C, Boyle P. Metaanalysis of studies on breast cancer risk and diet: the role of fruit and vegetable consumption and the intake of associated micronutrients. Eur J Cancer 2000; 36(5): 636-646.

32. Drewnowski A, Rock CL, Henderson SA, et al. Serum beta-carotene and vitamin $\mathrm{C}$ as biomarkers of vegetable and fruit intakes in a community-based sample of French adults. Am J Clin Nutr 1997; 65(6): 1796-1802.

33. Forman MR, Beecher GR, Lanza E, et al. Effect of alcohol consumption on plasma carotenoid concentrations in premenopausal women: a controlled dietary study. Am J Clin Nutr 1995; 62(1): 131-135.

34. Galan P, Viteri FE, Bertrais $S$, et al. Serum concentrations of beta-carotene, vitamins $\mathrm{C}$ and $\mathrm{E}$, zinc and selenium are influenced by sex, age, diet, smoking status, alcohol consumption and corpulence in a general French adult population. Eur J Clin Nutr 2005; 59(10): 1181-1190.

35. Le ML, Franke AA, Custer L, Wilkens LR, Cooney RV. Lifestyle and nutritional correlates of cytochrome CYP1A2 activity: inverse associations with plasma lutein and alpha-tocopherol. Pharmacogenetics 1997; 7(1): 11-19.

36. Nishino H, Tokuda H, Murakoshi M, et al. Cancer prevention by natural carotenoids. Biofactors 2000; 13(1-4): 89-94.

37. Wang XD. Alcohol, vitamin A, and cancer. Alcohol 2005; 35(3): 251-258.

38. Zhang S, Hunter DJ, Hankinson SE, et al. A prospective study of folate intake and the risk of breast cancer. JAMA 1999; 281(17): 1632-1637.

39. Baglietto L, English DR, Gertig DM, Hopper JL, Giles GG. Does dietary folate intake modify effect of alcohol consumption on breast cancer risk? BMJ 2005; 331(7520): 807.

40. Levi F, Pasche C, Lucchini F, La VC. Dietary intake of selected micronutrients and breast-cancer risk. Int $J$ Cancer 2001; 91(2): 260-263.

41. Sellers TA, Kushi LH, Cerhan JR, et al. Dietary folate intake, alcohol, and risk of breast cancer in a prospective study of postmenopausal women. Epidemiology 2001; 12(4): 420-428.

42. Feigelson HS, Jonas CR, Robertson AS, et al. Alcohol, folate, methionine, and risk of incident breast cancer in the American Cancer Society Cancer Prevention Study II Nutrition Cohort. Cancer Epidemiol Biomarkers Prev 2003; 12(2): 161-164.

43. Duthie SJ. Folic acid deficiency and cancer: mechanisms of DNA instability. Br Med Bull 1999; 55(3): 578-592.

44. Blount BC, Mack MM, Wehr CM, et al. Folate deficiency causes uracil misincorporation into human DNA and chromosome breakage: implications for cancer and neuronal damage. Proc Natl Acad Sci USA 1997; 94(7): 3290-3295.

45. Friso S, Choi SW. Gene-nutrient interactions and DNA methylation. J Nutr 2002; 132(8 Suppl): 2382S-2387S.

46. Friso S, Choi SW, Girelli D, et al. A common mutation in the 5,10-methylenetetrahydrofolate reductase gene affects genomic DNA methylation through an interaction with folate status. Proc Natl Acad Sci USA 2002; 99(8): 5606-5611.

47. Choi SW, Mason JB. Folate and carcinogenesis: an integrated scheme. J Nutr 2000; 130(2):129-132.

48. Fenech M, Aitken C, Rinaldi J. Folate, vitamin B12, homocysteine status and DNA damage in young Australian adults. Carcinogenesis 1998; 19(7): 1163-1171.

49. Hussien MM, McNulty $\mathrm{H}$, Armstrong $\mathrm{N}$, et al. Investigation of systemic folate status, impact of alcohol intake and levels of DNA damage in mononuclear cells of breast cancer patients. Br J Cancer 2005; 92(8): 1524-1530.

50. Kim YI. Folate and carcinogenesis: evidence, mechanisms, and implications. J Nutr Biochem 1999; 10(2): 66-88.

51. Smith SS, Crocitto L. DNA methylation in eukaryotic chromosome stability revisited: DNA methyltransferase in the management of DNA conformation space. Mol Carcinog 1999; 26(1): 1-9.

52. Ursin G, Hovanessian-Larsen L, Parisky YR, Pike MC, $\mathrm{Wu} \mathrm{AH}$. Greatly increased occurrence of breast cancers in areas of mammographically dense tissue. Breast Cancer Res 2005; 7(5): R605-R608.

53. Kerlikowske K, Shepherd J, Creasman J, et al. Are breast density and bone mineral density independent risk factors for breast cancer? J Natl Cancer Inst 2005; 97(5): 368-374.

54. Boyd NF, Byng JW, Jong RA, et al. Quantitative classification of mammographic densities and breast cancer risk: results from the Canadian National Breast Screening Study. J Natl Cancer Inst 1995; 87(9): 670-675.

55. Brisson J, Merletti F, Sadowsky NL, et al. Mammographic features of the breast and breast cancer risk. Am J Epidemiol 1982; 115(3):428-437.

56. Boyd NF, Lockwood GA, Martin LJ, et al. Mammographic density as a marker of susceptibility to breast cancer: a hypothesis. IARC Sci Publ 2001; 154: 163-169.

57. Byrne C, Schairer C, Brinton LA, et al. Effects of mammographic density and benign breast disease on breast cancer risk (United States). Cancer Causes Control 2001; 12(2):103-110.

58. Atkinson C, Warren R, Bingham SA, Day NE. Mammographic patterns as a predictive biomarker of breast cancer risk: effect of tamoxifen. Cancer Epidemiol Biomarkers Prev 1999; 8(10): 863-866.

59. Boyd NF, Lockwood GA, Byng JW, Tritchler DL, Yaffe MJ. Mammographic densities and breast cancer risk. Cancer Epidemiol Biomarkers Prev 1998; 7(12): 1133-1144.

60. Harvey JA, Bovbjerg VE. Quantitative assessment of mammographic breast density: relationship with breast cancer risk. Radiology 2004; 230(1): 29-41.

61. Boyd NF, Connelly P, Byng J, et al. Plasma lipids, lipoproteins, and mammographic densities. Cancer Epidemiol Biomarkers Prev 1995; 4(7): 727-733.

62. Vachon CM, Kuni CC, Anderson K, Anderson VE, Sellers TA. Association of mammographically defined percent breast density with epidemiologic risk factors for breast cancer (United States). Cancer Causes Control 2000; 11(7): 653-662.

63. Byrne C. Studying mammographic density: implications for understanding breast cancer. J Natl Cancer Inst 1997; 89(8): 531-533.

64. Singletary KW, McNary MQ. Effect of moderate ethanol consumption on mammary gland structural development 
and DNA synthesis in the female rat. Alcohol 1992; 9(2): 95-101.

65. Vachon CM, Kushi LH, Cerhan JR, Kuni CC, Sellers TA. Association of diet and mammographic breast density in the Minnesota breast cancer family cohort. Cancer Epidemiol Biomarkers Prev 2000; 9(2): 151-160.

66. Mihas AA, Hung PG, Heuman D. Alcoholic Hepatitis. http://www.emedicine.com/med/topic101.htm. 2005.

67. Seitz HK, Poschl G, Simanowski UA. Alcohol and cancer. Recent Dev Alcohol 1998; 14: 67-95.

68. Purohit V, Khalsa J, Serrano J. Mechanisms of alcoholassociated cancers: introduction and summary of the symposium. Alcohol 2005; 35(3): 155-160.

69. Castro GD, gado de Layno AM, Costantini $M H$, Castro JA. Cytosolic xanthine oxidoreductase mediated bioactivation of ethanol to acetaldehyde and free radicals in rat breast tissue. Its potential role in alcohol-promoted mammary cancer. Toxicology 2001; 160(1-3):11-18.

70. Soffritti M, Belpoggi F, Lambertin L, et al. Results of long-term experimental studies on the carcinogenicity of formaldehyde and acetaldehyde in rats. Ann NY Acad Sci 2002; 982: 87-105.

71. Obe G, Anderson D. International Commission for Protection against Environmental Mutagens and Carcinogens. ICPEMC Working Paper No. 15/1. Genetic effects of ethanol. Mutat Res 1987; 186(3): 177-200.

72. Ishii H, Kurose I, Kato S. Pathogenesis of alcoholic liver disease with particular emphasis on oxidative stress. J Gastroenterol Hepatol 1997; 12(9-10): S272-S282.

73. Russo J, Russo IH. Cellular basis of breast cancer susceptibility. Oncol Res 1999; 11(4):169-178.

74. Maltoni C, Ciliberti A, Cotti G, Conti B, Belpoggi F. Benzene, an experimental multipotential carcinogen: results of the long-term bioassays performed at the Bologna Institute of Oncology. Environ Health Perspect 1989; 82: 109-124.

75. Guengerich FP, Kim DH, Iwasaki M. Role of human cytochrome P-450 IIE1 in the oxidation of many low molecular weight cancer suspects. Chem Res Toxicol 1991; 4(2): 168-179.

76. Lieber CS. Cytochrome P-4502E1: its physiological and pathological role. Physiol Rev 1997; 77(2): 517-544.

77. Takahashi T, Lasker JM, Rosman AS, Lieber CS. Induction of cytochrome P-4502E1 in the human liver by ethanol is caused by a corresponding increase in encoding messenger RNA. Hepatology 1993; 17(2): 236-245.

78. Singletary KW, McNary MQ, Odoms AM, Nelshoppen J, Wallig MA. Ethanol consumption and DMBA-induced mammary carcinogenesis in rats. Nutr Cancer 1991; 16(1): 13-23.

79. Singletary K, Nelshoppen J, Wallig M. Enhancement by chronic ethanol intake of $\mathrm{N}$-methyl-N-nitrosoureainduced rat mammary tumorigenesis. Carcinogenesis 1995; 16(4): 959-964.

80. Liehr JG, Jones JS. Role of iron in estrogen-induced cancer. Curr Med Chem 2001; 8(7): 839-849.

81. Elliott RL, Elliott MC, Wang F, Head JF. Breast carcinoma and the role of iron metabolism. A cytochemical, tissue culture, and ultrastructural study. Ann N Y Acad Sci 1993; 698: 159-166.

82. Petersen DR. Alcohol, iron-associated oxidative stress, and cancer. Alcohol 2005; 35(3): 243-249.

83. Brooks PJ, Theruvathu JA. DNA adducts from acetaldehyde: implications for alcohol-related carcinogenesis. Alcohol 2005; 35(3): 187-193.
84. Singletary KW, Barnes SL, van Breemen RB. Ethanol inhibits benzo[a]pyrene-DNA adduct removal and increases 8-oxo-deoxyguanosine formation in human mammary epithelial cells. Cancer Lett 2004; 203(2): 139-144.

85. Anderson LM, Chhabra SK, Nerurkar PV, Souliotis VL, Kyrtopoulos SA. Alcohol-related cancer risk: a toxicokinetic hypothesis. Alcohol 1995; 12(2): 97-104.

86. Yu H, Rohan T. Role of the insulin-like growth factor family in cancer development and progression. $J$ Natl Cancer Inst 2000; 92(18): 1472-1489.

87. Westley BR, Clayton SJ, Daws MR, Molloy CA, May FE. Interactions between the oestrogen and insulin-like growth factor signalling pathways in the control of breast epithelial cell proliferation. Biochem Soc Symp 1998; 63: 35-44.

88. de la Monte SM, Ganju N, Tanaka S, et al. Differential effects of ethanol on insulin-signaling through the insulin receptor substrate-1. Alcohol Clin Exp Res 1999; 23(5): 770-777.

89. Srivastava V, Hiney JK, Nyberg CL, Dees WL. Effect of ethanol on the synthesis of insulin-like growth factor 1 (IGF-1) and the IGF-1 receptor in late prepubertal female rats: a correlation with serum IGF-1. Alcohol Clin Exp Res 1995; 19(6): 1467-1473.

90. Seiler AE, Ross BN, Green JS, Rubin R. Differential effects of ethanol on insulin-like growth factor-I receptor signaling. Alcohol Clin Exp Res 2000; 24(2): 140-148.

91. Mukherjee JJ, Huang JS, Getman C, Kiss Z. Bombesin promotes synergistic stimulation of DNA synthesis by ethanol and insulin in fibroblasts. Arch Biochem Biophys 1999; 362(1): 183-189.

92. Benassi B, Fenech M. Alcohol, genome instability and breast cancer. Asia Pac J Clin Nutr 2004; 13(Suppl): S55.

93. Chen $\mathrm{Y}$, Lee WH, Chew HK. Emerging roles of BRCA1 in transcriptional regulation and DNA repair. J Cell Physiol 1999; 181(3): 385-392.

94. Singletary SE. Rating the risk factors for breast cancer. Ann Surg 2003; 237(4): 474-482.

95. Miki Y, Swensen J, Shattuck-Eidens D, et al. A strong candidate for the breast and ovarian cancer susceptibility gene BRCA1. Science 1994; 266(5182): 66-71.

96. Ford D, Easton DF, Bishop DT, Narod SA, Goldgar DE. Risks of cancer in BRCA1-mutation carriers. Breast Cancer Linkage Consortium. Lancet 1994; 343(8899): 692-695.

97. Fan S, Meng Q, Gao B, et al. Alcohol stimulates estrogen receptor signaling in human breast cancer cell lines. Cancer Res 2000; 60(20): 5635-5639.

98. Lee KM, Abel J, Ko Y, et al. Genetic polymorphisms of cytochrome P450 19 and 1B1, alcohol use, and breast cancer risk in Korean women. $\mathrm{Br} J$ Cancer 2003; 88(5): 675-678.

99. Semenza JC, Delfino RJ, Ziogas A, nton-Culver $H$. Breast cancer risk and methylenetetrahydrofolate reductase polymorphism. Breast Cancer Res Treat 2003; 77(3): 217-223.

100. Fearon ER, Vogelstein B. A genetic model for colorectal tumorigenesis. Cell 1990; 61(5): 759-767.

101. Greenblatt MS, Bennett WP, Hollstein M, Harris CC. Mutations in the p53 tumor suppressor gene: clues to cancer etiology and molecular pathogenesis. Cancer Res 1994; 54(18): 4855-4878.

102. Nass SJ, Herman JG, Gabrielson E, et al. Aberrant methylation of the estrogen receptor and E-cadherin $5^{\prime} \mathrm{CpG}$ 
islands increases with malignant progression in human breast cancer. Cancer Res 2000; 60(16): 4346-4348.

103. Pogribny IP, Poirier LA, James SJ. Differential sensitivity to loss of cytosine methyl groups within the hepatic p53 gene of folate/methyl deficient rats. Carcinogenesis 1995; 16(11): 2863-2867.

104. Giovannucci E. Alcohol, one-carbon metabolism, and colorectal cancer: recent insights from molecular studies. J Nutr 2004; 134(9): 2475S-2481S.

105. Laufer EM, Hartman TJ, Baer DJ, et al. Effects of moderate alcohol consumption on folate and vitamin $\mathrm{B}(12)$ status in postmenopausal women. Eur J Clin Nutr 2004; 58(11): 1518-1524.

106. Coutelle C, Hohn B, Benesova M, et al. Risk factors in alcohol associated breast cancer: alcohol dehydrogenase polymorphism and estrogens. Int J Oncol 2004; 25(4): 1127-1132.

107. Freudenheim JL, Ambrosone CB, Moysich KB, et al. Alcohol dehydrogenase 3 genotype modification of the association of alcohol consumption with breast cancer risk. Cancer Causes Control 1999; 10(5): 369-377.

108. Hines LM, Hankinson SE, Smith-Warner SA, et al. A prospective study of the effect of alcohol consumption and $\mathrm{ADH} 3$ genotype on plasma steroid hormone levels and breast cancer risk. Cancer Epidemiol Biomarkers Prev 2000; 9(10): 1099-1105.

109. Lilla C, Koehler T, Kropp S, Wang-Gohrke S, ChangClaude J. Alcohol dehydrogenase 1B (ADH1B) genotype, alcohol consumption and breast cancer risk by age 50 years in a German case-control study. $\mathrm{Br} J$ Cancer 2005; 92(11): 2039-2041.

110. Frosst $\mathrm{P}$, Blom HJ, Milos R, et al. A candidate genetic risk factor for vascular disease: a common mutation in methylenetetrahydrofolate reductase. Nat Genet 1995; 10(1): 111-113.

111. Guenther BD, Sheppard CA, Tran P, et al. The structure and properties of methylenetetrahydrofolate reductase from Escherichia coli suggest how folate ameliorates human hyperhomocysteinemia. Nat Struct Biol 1999; 6(4): 359-365.

112. Yamada K, Chen Z, Rozen R, Matthews RG. Effects of common polymorphisms on the properties of recombinant human methylenetetrahydrofolate reductase. Proc Natl Acad Sci USA 2001; 98(26): 14853-14858.

113. Le ML, Haiman CA, Wilkens LR, Kolonel LN, Henderson BE. MTHFR polymorphisms, diet, HRT, and breast cancer risk: the multiethnic cohort study. Cancer Epidemiol Biomarkers Prev 2004; 13(12): 2071-2077.
114. Chen J, Giovannucci E, Kelsey K, et al. A methylenetetrahydrofolate reductase polymorphism and the risk of colorectal cancer. Cancer Res 1996; 56(21): 4862-4864.

115. Ma J, Stampfer MJ, Giovannucci E, et al. Methylenetetrahydrofolate reductase polymorphism, dietary interactions, and risk of colorectal cancer. Cancer Res 1997; 57(6): 1098-1102.

116. Ulrich CM, Kampman E, Bigler J, et al. Colorectal adenomas and the C677T MTHFR polymorphism: evidence for gene-environment interaction? Cancer Epidemiol Biomarkers Prev 1999; 8(8): 659-668.

117. Bailey LB. Folate, methyl-related nutrients, alcohol, and the MTHFR $677 \mathrm{C} \rightarrow$ T polymorphism affect cancer risk: intake recommendations. J Nutr 2003; 133(11 Suppl 1): 3748S-3753S.

118. Choi JY, Abel J, Neuhaus T, et al. Role of alcohol and genetic polymorphisms of CYP2E1 and ALDH2 in breast cancer development. Pharmacogenetics 2003; 13(2): $67-72$.

119. Kim SU, Lee KM, Park SK, et al. Genetic polymorphism of glutathione S-transferase P1 and breast cancer risk. J Biochem Mol Biol 2004; 37(5): 582-585.

120. Zheng T, Holford TR, Zahm SH, et al. Glutathione Stransferase $\mathrm{M} 1$ and $\mathrm{T} 1$ genetic polymorphisms, alcoho consumption and breast cancer risk. Br J Cancer 2003; 88(1): 58-62.

121. Onland-Moret NC, Peeters PH, van der Schouw YT, Grobbee DE, van Gils $\mathrm{CH}$. Alcohol and endogenous sex steroid levels in postmenopausal women: a crosssectional study. J Clin Endocrinol Metab 2005; 90(3): 1414-1419.

122. Ginsburg ES. Estrogen, alcohol and breast cancer risk. J Steroid Biochem Mol Biol 1999; 69(1-6): 299-306.

123. Verkasalo PK, Thomas HV, Appleby PN, Davey GK, Key TJ. Circulating levels of sex hormones and their relation to risk factors for breast cancer: a cross-sectional study in 1092 pre- and postmenopausal women (United Kingdom). Cancer Causes Control 2001; 12(1): 47-59.

124. Cooper GS, Sandler DP, Whelan EA, Smith KR. Association of physical and behavioral characteristics with menstrual cycle patterns in women age 29-31 years. Epidemiology 1996; 7(6): 624-628.

125. Sarkar DK, Liehr JG, Singletary KW. Role of estrogen in alcohol promotion of breast cancer and prolactinomas. Alcohol Clin Exp Res 2001; 25(5 Suppl ISBRA): 230S-236S. 